\title{
Tackling variability of clay to provide a robust binder
}

\section{Conference Paper}

Author(s):

Ardant, Daria; Brumaud, Coralie; Habert, Guillaume

Publication date:

2022-01

Permanent link:

https://doi.org/10.3929/ethz-b-000492074

Rights / license:

In Copyright - Non-Commercial Use Permitted

Originally published in:

1, https://doi.org/10.4028/www.scientific.net/CTA.1.382 


\title{
TACKLING VARIABILITY OF CLAY TO PROVIDE A ROBUST BINDER
}

\author{
D. Ardant ${ }^{1 *}$, C. Brumaud ${ }^{1}$, G. Habert ${ }^{1}$ \\ ${ }^{1}$ Institute of Construction and Infrastructure Management, Chair of Sustainable Construction, \\ ETH Zurich, Stefano-Franscini-Platz 5, Zürich 8093, Switzerland
}

\begin{abstract}
Locally available and with infinite recycling possibilities, the use of earth as building material leads to one of the lowest environmental impacts in the construction sector. Recent advances in the earth materials field have been made based on concrete and ceramics technologies to facilitate its uses in dense areas. It is possible to modify clay particle interactions and the material's whole behavior by adding inorganic dispersants and flocculants into clay paste. Earth becomes easy to cast and unmold into formworks, and by removing cement in its composition, poured earth can reach a low $\mathrm{CO}_{2}$ emission rate. Even if this technology is promising, further work has to be performed, as it cannot be implemented on earth from excavation sites with high variability. Tackling the clay nature variability is now the main issue to push this product on the market with robust properties.

This research investigates the robustness of the poured earth binder. In this way, several clays (three montmorillonites, two kaolinites, and binary mixes at different proportions) were investigated. Their compacity $(\mathrm{C})$ was determined following the water demand protocol with Vicat apparatus and compared to their consistency properties (liquidity and plasticity limits), and a correlation between these values is established. Different clay pastes prepared at different solid volume fractions were tested to define the influence of the clay nature on the paste consistency evolution. The results showed that clay nature for paste at high solid volume fraction does not influence constituency's evolution when their respectivecompacity is taking into account. It can be suggested that for a clay binder with a consistency close to $\mathrm{C}$, which might be mandatory for poured earth application, only the swelling capacity might influence the mix design.
\end{abstract}

Keywords: Self-compacted clay concrete, variability, compacity, clay properties

\section{INTRODUCTION}

Because of city growth, a large amount of excavated earth is produced every year. By looking at the material flow in cities, this resource quantity is huge and appears as the main urban resource (Llatas, 2011; Vieira and Pereira, 2015). This excavated material as raw material for construction can be seen as the best example of a closed material flow loop with the best recycling potential (Gasnier, 2016; Hamard et al., 2018). It can provide, in the end, one of the building materials with the lowest environmental impact. However, to transform this strong potential resource into construction material, earth construction needs to become less marginal in the urban context. The complicated process used, the high variability of the raw material, the execution speed, and the labor cost limit its larger expansion and industrialization. Consequently, two main questions still need to be addressed to make this use possible.

Firstly, developing a technology that could facilitate the quick use of excavated earth on-site is critically needed in this context. Based on the combination of concrete and ceramic technologies, research has been done to develop a material that is as easy and cheap to use as current concrete products. This approach is possible because clays share many similarities with cementitious materials in terms of colloidal interactions and adhesion forces (Pellenq and Van Damme, 2004). During the last decade, strategies have been investigated to develop poured earth without any hydraulic binder. These different approaches all use clay dispersants coming from the ceramic industry, mainly sodium hexametaphosphate (NaHMP), to allow the material to flow with a limited amount of water (Ardant et al., 2020; Landrou et al., 2018; Moevus et al., 2016; Perrot et al., 2018b; Pinel et al., 2017). All these strategies show an increase in global strength thanks to the dispersant action as the clay platelets' initially positive edge charges become negative.

However, the fresh and hardened properties of final poured earth material differ substantially from one type of clay to another, making this strategy not robust. Moreover, the electrostatic dispersant action such as NaHMP on binder is highly linked to clay nature (Castellini et al., 2013; Guihéneuf, 2020). It is why, secondly, a better understanding of the influence of earth's variability on the poured earth properties is needed. Some studies already explored this 
variability for different earth techniques (Hamard et al., 2018; Julloux, 2020; Rojat et al., 2020; Vinceslas, 2019) and have highlighted different key parameters, such as particle size distribution or cation exchange capacity (CEC).

For poured earth application, high concentrated clay paste seems needed to reduce the shrinkage and increase the global strength. For instance, there is still a lack of knowledge on the influence of clay nature on the fresh and hardened state properties of a dense clay binder. This paper focuses on fresh binder properties. Five different pastes with a high concentration of clay (three montmorillonites and two kaolinites) were tested as well as their binary mixes. Their compacity was determined and compared to their consistency properties (Atterberg limits). Different clay pastes were prepared at different solid volume fractions and tested to define if clay nature influences the paste consistency evolution at high concentrations.

\section{MATERIALS AND MEASUREMENT PROCEDURES}

\subsection{Clay}

Five different pure clays were used in this study, varying by their physical properties:

- Two kaolinites: White kaolinite (referred to here as KA) sourced from Argile du Bassin Mediterranéen (France), and kaolinite FP80 (referred to here as KF) sourced from Dorfner (Germany)

- $\quad$ Three montmorillonites: Red montmorillonite (referred to here as MR), green montmorillonite (referred to here as $M G$ ), beige montmorillonite (referred to here as MB). All are sourced from Argile du Bassin Mediterranéen (Sardinia).

Their main physicochemical properties are gathered in Tab.1. The median particle size $D_{50}$ of the clay has been evaluated with an automated particle size analyzer (Pario, Metter, Switzerland). The specific density has been determined with a water pycnometer and the methylene blue value (MBV) with a methylene blue test kit. Finally, physicochemical properties have been measured via X-Ray diffraction analysis (XRD). Besides, different kaolinite/montmorillonite binary mixes in different volume proportions were studied.

Tab. 1: Main physicochemical properties of the clays studied here

\begin{tabular}{|c|c|c|c|c|c|}
\hline Clay & KA & KF & MR & MG & MB \\
\hline $\mathrm{D} 50(\mu \mathrm{m})$ & 1.58 & 2.7 & 1.52 & 1.4 & 0.8 \\
\hline Specific density & 2.543 & 2.62 & 2.463 & 2.422 & 2.365 \\
\hline MBV & 2.33 & 1.33 & 21 & 32 & 22 \\
\hline \multicolumn{6}{|l|}{ Chemical analysis by XRD } \\
\hline Ca-Montmorillonite (\%) & & & 65 & 83.6 & 67.6 \\
\hline Kaolinite (\%) & 87.1 & 87.2 & & & \\
\hline Muscovite (\%) & 10.7 & 6.05 & 20 & 10.7 & \\
\hline Andesine (\%) & & & & & 20.3 \\
\hline Quartz, calcite (\%) & 2.2 & 1.5 & 7.2 & 3.7 & 3.7 \\
\hline Other (\%) & 0 & 5.25 & 7.8 & 2 & 8.4 \\
\hline
\end{tabular}

\subsection{Clay polder compacity}

The clay powder compacity (C) was measured through the water demand protocol according to (Sedran et al., 2007). An increasing amount of water was added to $250 \mathrm{~g}$ of powder and mixed with a four-bladed mixing tool connected to a mechanical stirrer (Heidolph, Switzerland) for $3 \mathrm{~min}$ at $350 \mathrm{rpm}$. After mixing, the Vicat truncated cone (Vicatronic, Matest, Switzerland) was filled with the material and placed under the consistency needle $(10 \mathrm{~mm}$ diameter). According to the protocol, the needle's penetration depth in free fall was measured, and the dense volume fraction is reached when the penetration depth is of $6 \mathrm{~mm}$. The water content of all mixes is then obtained by heating the paste at $105^{\circ} \mathrm{C}$ in the oven. Two measurements have been performed on pure clay and one on mixed clays. The compacity value is determined following the equation given by (Sedran et al., 2007).

\subsection{Atterberg limits}

The liquidity limit is determined using the fall cone method with a cone dial penetrometer (Matest, Switzerland) equipped with a stainless steel penetration test cone of $35 \mathrm{~mm}$ length, $30^{\circ}$ angle, for a total weight of $80 \mathrm{~g}$. This test consists of determining the paste's water content after drying at $105^{\circ}$, for a penetration depth of $20 \mathrm{~mm}$. This method is considered more accurate than the Casagrande method (Koumoto and Houlsby, 2001), reducing the operator's potential influence. The fall cone test can also be used to determine the plastic limit, corresponding to a penetration depth of $2 \mathrm{~mm}$, by using a log-log curve fitting of the penetration depth versus water content relationship (Feng, 2001). As for the clay polder compacity, two measurements have been performed on pure clay and one on mixed clays. The liquidity limit obtained, corresponding to the water to clay ratio, is then used to determine the correlated solid volume fraction $\Phi_{\mathrm{LL}}$ by using the equation exposed in 2.2 . 


\section{RESULTS AND DISCUSSION}

In Fig. 1, each clay powder compacity $(C)$ is plotted as a function of their solid volume fraction related to the liquidity limit value $\left(\Phi_{\mathrm{LL}}\right)$. Both results seem close with good repeatability for all the clays, as only high swelling clays show a variation between the performed measurements. Consequently, the penetrometer appears as a suitable tool for measuring the fine fraction compacity as this value can be calculated at the liquidity limit consistency.

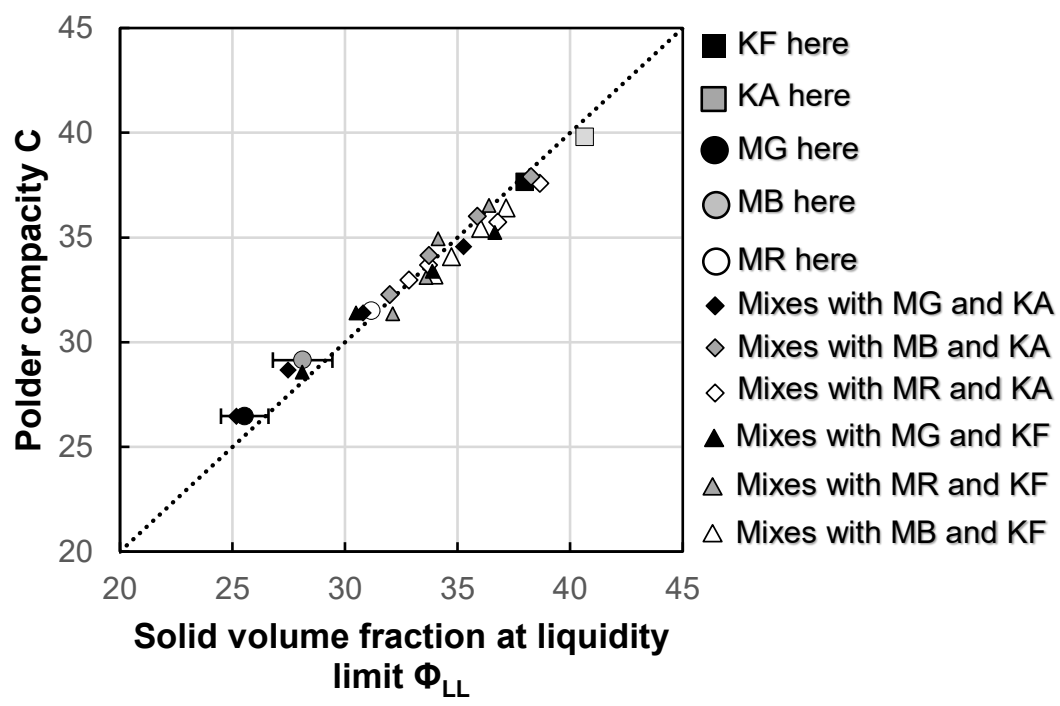

Fig. 1:Correlation between polder compacity and solid volume fraction value at liquidity limit

In the geotechnical field, the fall cone has been used to determine the soil yield stress in relationship with the penetration depth reached (Fitton and Seddon, 2012; Perrot et al., 2018, 2016). With the equipment used here, when the penetration depth reaches $20 \mathrm{~mm}$, corresponding to the clay liquidity limit value, the correlated yield stress is evaluated around $2 \mathrm{kPa}$. A similar relationship between equipment characteristics, depth penetration, and yield stress has been done with Vicat instrument on cement paste (Lootens et al., 2009). With the equipment used here, when the penetration depth reaches $6 \mathrm{~mm}$, corresponding to the fine powder compacity determination, the correlated yield stress is also evaluated around $2 \mathrm{kPa}$. As the binder's nature is not considered in the related equation, it is possible to compare these two values even if used on different materials. Consequently, it can be assumed that when one clay is at its liquidity limit, it reaches its dense volume fraction, and the related paste exhibits yield stress around $2 \mathrm{kPa}$.

To better view how the paste consistency is evolving according to its solid volume fraction, the penetration depth, linked to the paste consistency (Andrade et al., 2011), is plotted as a function of the solid volume fraction (Ф) (Fig. 2.a). As expected, for each clay, when the solid volume fraction increases, the penetration depth decreases as the paste becomes denser. The solid volume fraction is then normalized by each clay's compacity (Fig.2.b).
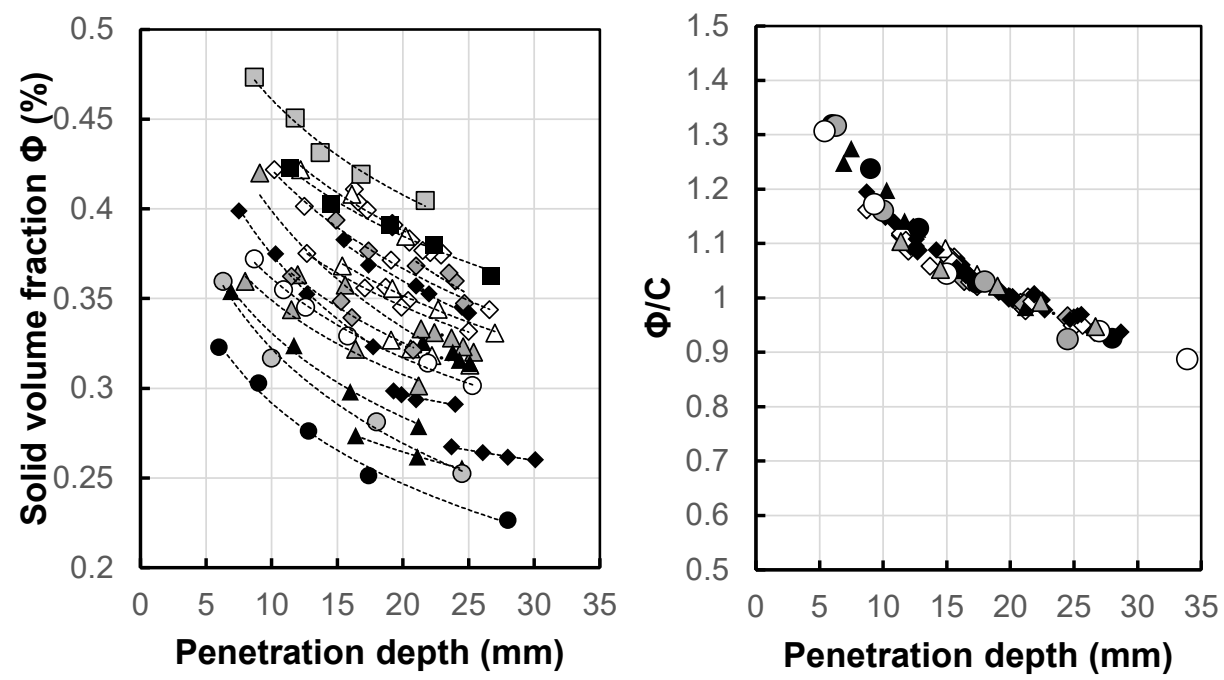

KF here

$\square$ KA here

MG here

$\mathrm{OMB}$ here

O MR here

- Mixes with MG and $\mathrm{K}$

$\diamond$ Mixes with $\mathrm{MB}$ and $\mathrm{K}$

$\diamond$ Mixes with MR and $\mathrm{K}$

$\triangle$ Mixes with MG and KF

$\triangle$ Mixes with MR and KF

$\triangle$ Mixes with MB and KF

Fig. 2: a) Evolution of solid volume fraction according to penetration depth. b) Evolution of normalized solid volume fraction of paste by their concentration at liquidity limit according to penetration depth. 
Based on these results, it can be observed that all clays present the same evolution of paste consistency. Diffraction can be seen for solid volume fraction higher than 1.1 times the compacity value, which can be explained by the protocol's difficulties to have repeatable results at low water content. As suggested in (Perrot et al., 2016) and applied in (Perrot et al., 2018; Tourtelot et al., 2021), a solution to increase this accuracy would be to add weight to the needle, which will consequently increase the penetration depth accuracy.

It can be suggested that, for paste with a consistency close to the one at its liquidity limit, the only main parameter influencing paste properties is the water absorption. This observation might not be similar for paste with a low solid volume fraction. In (Fitton and Seddon, 2012), it has been shown on mine tailing materials that particle size influences the paste yield stress evolution when the solid concentration is much lower than the one at the liquidity limit. Further research needs to be done on lower solid volume fractions to define when clay properties, such as particle size, start to interfere in the paste's yield stress evolution. However, the clay paste needs to have a high solid volume fraction for poured earth application to reduce the shrinkage. It is then possible to suggest that this application's required paste consistency will be in the threshold between the liquidity limit and plasticity limit.

\section{CONCLUSION}

In this study, a correlation between solid volume fraction value at liquidity limit and compacity value has been established for different rich clay powders. Results show that a penetrometer can be used without adaptation for measuring the dense volume fraction. This link between concrete and geotechnical fields reinforces the idea of similarity between earth and concrete. Based on this correlation, the normalized concentration value, defined by normalizing the solid volume fraction values $\Phi$ by the compacity value, is similar for each clay. It becomes possible to anticipate a consistency value through known water to clay ratio when the liquidity limit has been determined.

Thanks to research on yield stress and penetration depth, it is possible to suppose that clay nature might not influence the paste's evolution yield stress when the paste has a consistency between its liquidity and plasticity limit. Knowing that fine particles' properties influence the paste's evolution yield stress when the paste is at a low concentration, the threshold between these two results needs to be defined.

For poured earth, high concentrated clay paste seems needed to reduce shrinkage and increase global strength. We can then suggest that paste used as the binder for this application will be between its liquidity and plasticity limit. Consequently, clay nature might not impact the binder constituency's evolution when the water to clay ratio evolved. This possibility could be view as an improvement to tackle the problem of earth variability for poured earth application.

\section{REFERENCES}

Andrade, F.A., Al-Qureshi, H.A., Hotza, D., 2011. Measuring the plasticity of clays: A review. Appl. Clay Sci. https://doi.org/10.1016/j.clay.2010.10.028

Ardant, D., Brumaud, C., Habert, G., 2020. Influence of additives on poured earth strength development. Mater. Struct. Constr. 53, 1-17. https://doi.org/10.1617/s11527-020-01564-y

Castellini, E., Berthold, C., Malferrari, D., Bernini, F., 2013. Sodium hexametaphosphate interaction with 2:1 clay minerals illite and montmorillonite. Appl. Clay Sci. 83-84, 162-170. https://doi.org/10.1016/j.clay.2013.08.031

Feng, T.-W., 2001. A linear log $d-\log w$ model for the determination of consistency limits of soils . Can. Geotech. J. 38, 1335-1342. https://doi.org/10.1139/t01-061

Fitton, T., Seddon, K., 2012. Relating Atterberg limits to rheology, in: Proceedings of the 15th International Seminar on Paste and Thickened Tailings. Australian Centre for Geomechanics, Perth, pp. 273-284. https://doi.org/10.36487/acg_rep/1263_23_fitton

Gasnier, H., 2019. Construire en terres d'excavation, un enjeu pour la ville durable. (PhD Thesis). Université Grenoble Alpes (CoMue). France

Guihéneuf, S., 2020. Formulation et renforts de blocs en matériau terre pour une utilisation structurelle. (PhD Thesis) Université de Bretagne Sud, France.

Julloux, A., Brumaud, C., Habert, G., Perrot, A., 2020. Variability of clay in poured earth, in: Proceedings of the $8^{\text {th }}$ Internationale Fachtagung für Lehmbau (LEHM 2020) (virtual), Online Weimar: Dachverband Lehm e.V.,

Hamard, E., Lemercier, B., Cazacliu, B., Razakamanantsoa, A., Morel, J.C., 2018. A new methodology to identify and quantify material resource at a large scale for earth construction - Application to cob in Brittany. Constr. 
Build. Mater. 170, 485-497. https://doi.org/10.1016/j.conbuildmat.2018.03.097

Koumoto, T., Houlsby, G.T., 2001. Theory and practice of the fall cone test. Géotechnique 51, $701-712$. https://doi.org/10.1680/geot.2001.51.8.701

Landrou, G., Brumaud, C., Plötze, M.L., Winnefeld, F., Habert, G., 2018. A fresh look at dense clay paste: Deflocculation and thixotropy mechanisms. Colloids Surfaces A Physicochem. Eng. Asp. 539, $252-260$. https://doi.org/10.1016/j.colsurfa.2017.12.029

Llatas, C., 2011. A model for quantifying construction waste in projects according to the European waste list. Waste Manag. 31, 1261-1276. https://doi.org/10.1016/j.wasman.2011.01.023

Lootens, D., Jousset, P., Martinie, L., Roussel, N., Flatt, R.J., 2009. Yield stress during setting of cement pastes from penetration tests. Cem. Concr. Res. 39, 401-408. https://doi.org/10.1016/j.cemconres.2009.01.012

Moevus, M., Jorand, Y., Olagnon, C., Maximilien, S., Anger, R., Fontaine, L., Arnaud, L., 2016. Earthen construction: an increase of the mechanical strength by optimizing the dispersion of the binder phase. Mater. Struct. Constr. 49, 1555-1568. https://doi.org/10.1617/s11527-015-0595-5

Perrot, A., Rangeard, D., Lecompte, T., 2018. Field-oriented tests to evaluate the workability of cob and adobe. Mater. Struct. Constr. 51, 1-10. https://doi.org/10.1617/s11527-018-1181-4

Perrot, A., Rangeard, D., Levigneur, A., 2016. Linking rheological and geotechnical properties of kaolinite materials for earthen construction. Mater. Struct. Constr. https://doi.org/10.1617/s11527-016-0813-9

Pinel, A., Jorand, Y., Olagnon, C., Charlot, A., Fleury, E., 2017. Towards poured earth construction mimicking cement solidification: demonstration of feasibility via a biosourced polymer. Mater. Struct. Constr. 50, 1-17. https://doi.org/10.1617/s11527-017-1092-9

Rojat, F., Hamard, E., Fabbri, A., Carnus, B., McGregor, F., 2020. Towards an easy decision tool to assess soil suitability for earth building. Constr. Build. Mater. 257, 119544. https://doi.org/10.1016/j.conbuildmat.2020.119544

Sedran, T., De Larrard, F., Le Guen, L., 2007. Détermination de la compacité des ciments et additions minérales à la sonde de Vicat, Bulletin des Laboratoires des Ponts et Chaussées.

Vinceslas,T., 2019. Caractérisation d'éco-matériaux terre-chanvre en prenant en compte la variabilité des ressources disponibles localement. (PhD Thesis) Université de Bretagne Sud, France.

Tourtelot, J., Ghattassi, I., Le Roy, R., Bourgès, A., Keita, E., 2021. Yield stress measurement for earth-based building materials: the weighted plunger test. Mater. Struct. 54. https://doi.org/10.1617/s11527-020-01588-4

Vieira, C.S., Pereira, P.M., 2015. Use of recycled construction and demolition materials in geotechnical applications: A review. Resour. Conserv. Recycl. https://doi.org/10.1016/j.resconrec.2015.07.023 